\section{O SUPLÍCIO DE CUPIDO EM COMENTÁRIO E TRADUÇÃO}

Reina Marisol Troca Pereira*

RESUMO: O presente artigo apresenta dois momentos distintos. Primeiramente, regista-se um comentário sumário sobre o opúsculo de Ausónio intitulado Cupidus Cruciatus. Nessa ocasião verificam-se aspectos de uma obra na confluência de dois credos, com particular destaque para elementos como a crucificação, a religião, valores, figuras e símbolos. $\mathrm{O}$ artigo comporta, de igual modo, uma tradução do texto latino.

PALAVRAS-CHAVE: Eros/Cupido, crucificação, amor, sonho.

\section{CUPID'S TORMENT: COMMENTARY AND TRANSLATION}

\begin{abstract}
This paper presents two different chapters. First, there is a comment about the opusculum of Ausonius untitled Cupidus Cruciatus. On this occasion there are aspects of the literary work at the confluence of two faiths, with particular emphasis on elements such as crucifixion, religion, values, symbols, figures and symbols. Secondly, the article presents a complete translation of the Latin text.
\end{abstract}

KEYWORDS: Eros/Cupid, crucifixion, love, dream.

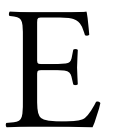

ros, o eterno inconsequente deus pueril, que flechava, nas suas brincadeiras, todas as criaturas, ${ }^{1}$ infectandoas com a patologia de infindáveis dores, ${ }^{2}$ surge também em retratos de uma inocência ternamente compungida. Demonstrando-se frágil, vulnerável e choroso, não prescinde de colo, afago e consolo materno - afinal, também o afectavam certas desaventuras, configurando um retrato agridulce (43-44: unlnera amorum $\mid$ dulcibus et maestis. Cf. $\gamma \lambda$ uкúmıкpos -Sapph. fr. 40 Bergk $)^{3}$ do topos amoroso e toldando atmosferas
* Universidade da Beira Interior, Portugal.
${ }^{1}$ Vd. Il.14.198-199. Cf. Pl. Smp. 186b.

${ }^{2}$ Vd. Nilsson 2009; Duffin 2005.

${ }^{3}$ Cf. O recurso literário à figura da abelha. Vd.

Teócrito 19: Kпргок $\lambda \varepsilon_{\text {émTnS, }}$

"O Usurpador de

Colmeias". Enquanto motivo literario, a picada de Eros por uma abelha tornou-se recorrente, encontrando-se, outrossim, na colectânea anacreôntica (34 Lindau $=$ 40 Davidson). Cf. Mel. carm. 108, Marc. Arg. ep. 2, Strat. ep. 88, Mod. $A L$. 347. Vd. Bonanno 1990; Rosenmeyer 2006; Lebek 1985. 
${ }^{4}$ Vd. Napiwocki 1985; Reeve 1977.

${ }^{5}$ Vd. Haldemann 2000; Hofmann 1999.

${ }^{6}$ Quiçá um filósofo e retórico do século IV a.C, ou talvez um outro contemporâneo de Ausónio.

A respeito da representação do

pensamento através de diferentes sistemas semióticos e, considerando, em particular, o processo de 'tradução intersemiótica' alegado na obra em apreço, vide, para uma contextualização teórica,

Plaza 2002; Santaella 2001; Mitchell 1994; Praz 1967.

${ }^{8}$ Cf. Gregório, figura que saúda como filius, termo que não terá que entenderse no sentido literal de descendente, mas porventura como uma forma de tratamento amigável para com uma entidade real ou já inserida na ficção. Sobre a possibilidade de tratar-se de Proculo Gregório, prefeito da Gália, no século IV, vd. Mondin 2005. Cf., em Eclogarum Liber, o nome de Drepanius. bucólicas e idílicas. Assim acoantece no imaginário literário de Cupido Cruciatur(s), de Décimo Magno Ausónio, na medievalidade latina tardia do século IV.

A obra pode referenciar-se mormente através de quatro grupos maiores de manuscritos, a saber: Z Tilianus; T Codex Tilianus / Leidensis Vossianus lat. Q. 107, que carece da produção posterior a 383; V Leidensis Vossianus lat. 111; P Parisinus 8500, para além dos excertos, apontados nos Excerpta de opusculis D. Magni Ausonii, onde se inclui G St. Gall 899. Quanto às fontes disponíveis, desde a editio princeps de 1472, em Veneza (G Bartholomaei Girardini), se umas carecem de algum material, outras compensam tais faltas, estabelecendo entre si, não uma lógica reprodutiva igualitária mas antes de complementaridade (cf. $\lambda$ Laurentianus 51, 113 - Magliabecchiani deperditae partes descriptae ab Al. Verrazano). ${ }^{4}$

Numa narrativa em jeito de prefácio, Ausónio classifica os seus hexâmetros intitulados Cupidus Cruciatus, ${ }^{5}$ enquanto ecloga. Partindo, nos momentos introdutórios, da ekphrasis contemplativa de uma pintura (tabulam picturam in parietem) visionada em Treveri, na sala de Zoilo, ${ }^{6}$ num acto de inspiração, resolve alterar o sistema semiótico. ${ }^{7}$ Traduz então os signos icónicos da imagem para os sinais linguísticos de uma composição que humildemente reporta, na missiva inicial, supostamente enviada a Gregório, ${ }^{8}$ como despretensiosa, numa modéstia convencional de autocrítica e de captatio beneuolentiae, ao bom jeito retórico de um escolástico que fora. Que a obra resultante se mostra de reduzidas dimensóes e sem grande aparato linguístico ou cuidado literário, parece de facto resultante de um improviso repentista face à dita imagem observada. Num evidente contraste, a inactividade do retrato fixo e estanque numa parede diverge do dinamismo que emite e que o escritor enfatiza, com pormenores sinestésicos, num reconto distribuído por três fases, partindo de um locus amoenus: logo a seguir a uma acalmia inicial, a descoberta/ira/punição de Cupido, por um conjunto paradigmático de mulheres de heróis sofridas por amores, que se lhes revelaram nefandos (Sémele, Cénis, Prócris, Safo, Eurípilo, Pasífae, Ariadne, Fedra, Laodamia, Tisbe, Cânace, Elisa, Mirrra, entre muitas outras centum aliae. Cf. sofrimentos masculinos: Narciso, Jacinto, Croco, Adónis, Eas de Salamina), em desvario. Sequiosas de 
retaliação vingativa, junta-se-lhes também Vénus (cf. Mel. $A P$ 178), matriz impulsionadora, porquanto também afectada cumpriam-se temores outrora previstos e prevenidos transversalmente no panorama literário da Antiguidade (e.g. Luciano de Samósata, DD. 20 Macleod). Segue-se o perdão e, por fim, o culminar com a deidade esvoaçante, rumo às alturas (euolat ad superos). O cenário contemplado configura uma trama que reúne matéria profusamente abordada em tempos prévios (e.g. Virgílio: Maro noster enumerat. Cf. 1: musa Maronis. Cf. Heroides ovidianas).?

Atendidas as devidas reservas, mutatis mutandis, a penalização imputada a Cupido pela justiça vingadora das heroides parece, de certa forma, parodiar elementos de um procedimento punitivo aplicado entre civilizaçōes do paganismo clássico - crucificare (cf. oтaupı́ós e, no latim dos cristãos, crucifigo, crucifixor), funcionando também como marco basilar do contexto judaico-cristão, pela paixão/crucificação de Cristo. ${ }^{10}$ Afinal, o Retórico de Burdigala demonstrava haver-se convertido ao Cristianismo (Cf. Parentalia, Domestica 2.24 sq., Griphus 1.88), embora provavelmente não se tivesse tornado um pio devoto. ${ }^{11}$ De toda a forma, o facto não o impedia de continuar a fazer uso de elementos pagãos, no caso de figuras, mas também de entidades religiosas, o que denotava a sobrevivência do paganismo mitológico, ainda que destituída de um cunho religioso, sob uma funcionalidade ornamental e didáctica. Eis, pois, a ocorrência, no opúsculo de Ausónio, de aspectos que relembram o martírio, a uia crucis, a corona rosea que configuram um continuum civilizacional. No seu todo, assiste-se a uma dicotomia de atmosferas e valores. De um lado, a factualidade de suplícios recorrentes, centrados na figura do Messias, agente de agape, afecto inquebrantável, unificador, desinteressado e nobilitante (e.g. 1Coríntios: 13:4-8. Cf. 1João 4:16).

$\mathrm{Na}$ vertente pagã, também longe de um 'Paraíso Celestial', no imaginário de Ausónio, o tradicional locus amoenus bucólico é substituído por um cenário lúgubre, denunciador de sofrimentos. Todavia, o tormento de Cupido possui um carácter onírico (porta eburna. cf. somni portae, uma com uerae umbrae, outra de falsa insomnia). ${ }^{12}$ De facto, todos os elementos da diegese, qual alegoria ficcionada sobre o topos da patologia amorosa, feita de simulacra ${ }^{13}$ circundamse de um cariz vão, efémero, falso, inconsistente. Assim
${ }^{9}$ A propósito dos modelos eventualmente seguidos por Ausónio, vd., a título ilustrativo, Vannuci 1989. Cf. Santini 2002; CharlesMarie 1986.

${ }^{10}$ Sobre o simbolismo da cruz na obra de Ausónio, vd. Garrod 1912 IXXLIII; Miller 2011.

${ }^{11}$ A respeito de Ausónio como escritor de transição, no referente a credos e culturas, cf. Edwards 1909, Fauth 1974.

${ }^{12}$ Cf. Penélope e a distinção da veracidade/ falsidade dos sonhos,

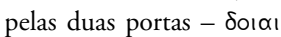
пú $\alpha_{1}$ - dos sonhos, uma

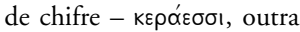

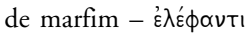
(Od.19.559-569). De igual forma, Virg. $A$. 8.22-28 denota a simbologia das geminae portae da seguinte forma: uma, a ebúrnea, falaz; outra conotada com a verdade - a de natureza cornígera. Vd. Harris 2009; Gindhart 2006; Tarrant 1982; O'Hara 1996. Cf. Cockburn 1992; Kilpatrick 1995.

${ }^{13}$ De salientar a simbologia do paralelismo das figuras do Sono e da Morte, representados por Hypnos e Thanatos, respectivamente. Apesar de, tradicionalmente, existir uma relação de fraternidade, constrói-se, na cena onírica de Cupido, uma morte passageira (vd. $I l$. 16.682; Hes. Th. 759. Cf. Paus. 18.1). 
${ }^{14}$ Vd. Catábases diversas: e.g. Ulisses (Od. 11); Eneias (Virg. A. 6.440476). Cf. lugentes campi (A. 6.440 sq.. Cf. Catul. 66). Relativamente a catábases em autores da Antiguidade Clássica, tanto no âmbito da cultura grega (e.g. epopeias homéricas), como em poetas romanos

(e.g. Virgílio), alguns certamente tidos como modelos de Ausónio, vide Kaufmann 2010; Davis 1994; Clark 1979; Laird 2001; Dominik 1996; Warden 2000.

Comportamento insolente típico da humanidade. Cf., para uma apreciação geral, Od. $1.32-34$.

\footnotetext{
${ }^{16}$ Verg. A. $6.440-451$.
}

também com o afecto induzido: um eros vulgar, fugaz, causador de tormentos. Porém, na cena literária, o imediatismo revolto da justiça vingadora, de matriz retributiva e taliónica, expressa na pena de crucificação, martírio composto pelas rosas e pela ligação ao tronco lenhoso, merece reconsideração/perdão, desvanecendo-se na íntegra com o término da catábase ${ }^{14}$ sonhada.

Entre o episódio retratado do âmbito judaico-cristão, com Cristo, e o retrato literário pagão, com Cupido, o confronto acompanha os momentos finais, assistindo-se, por um lado, a uma ressurreição, enquanto expoente de uma dinâmica de 'descida à terra' - 'ascensão/reencontro' 'descida ao plano sensorial'/'subida do solo'. Da parte da divindade, contempla-se uma descida às profundidades da consciência, através do sono - 'o abandono da catábase onírica' - 'o acordar do pesadelo'.

Confluem assim, no apontamento literário de Ausónio, aspectos como amor; religião; justiça-vingança-perdão; sonho; catábase; Hades; crucificação; episódios mitológicos.

A tradução latina abaixo reproduzida segue a lição veiculada em Peiper, R. (1886), D. Magni Ausonii Burdigalensis. Opuscula, Lipsiae, B. G. Teubneri: 107-113, completando a edição de 1823, D. Magni Ausonii Burdigalensis. Opera omnia, ex editione Bipontina cum notis et interpretatione recensita, 1, Londini, A. J. Valpy: 427-441, o verso 25, em falta.

\section{Carta-Prefácio}

Ausónio ao seu filho, Gregório,

\section{Saudações!}

Alguma vez viste um quadro pintado numa parede? Certamente já viste e estás recordado. Ora, em Treveri, de um triclínio de Zoilo, contempla-se a seguinte imagem pintada: Cupido a ser crucificado na cruz por certas mulheres menosprezadas no amor - não aquelas apaixonadas dos nossos dias, que caem na transgressão de livre-vontade, mas aquelas apaixonadas que se desculpabilizam e culpam os deuses. ${ }^{15}$ Algumas delas o nosso Virgílio ${ }^{16}$ dá conta na sua descrição dos Campos do Sofrimento. Fiquei bastante surpreendido pela arte e pela temática desta imagem. Subsequentemente, transformei a surpresa da minha admiração 
numa versificação insípida. Nada nela me satisfaz, excepto o título. Ainda assim, envio o meu falhanço ao teu cuidado. Amamos as nossas próprias verrugas e cicatrizes e, não satisfeitos ao errar com a nossa loucura, procuramos fazer com que os outros também as amem. Mas por que razão eu estou a sofrer tanto para explicar a causa desta écloga? Sei bem que irás gostar do que quer que saibas que é meu, e é mais isso que espero, do que o teu louvor. Adeus, e pensa com carinho sobre o teu pai.

\section{Cupido Crucificado}

"Nos aéreos campos, que relembra a musa de Marão, aí, onde o bosque de mirtilo encobre os amantes em desvario, as heroínas encontravam-se a executar ritos frenéticos, cada uma transportando relíquias da morte de quando havia expirado. E vagueando numa grande floresta, iluminada por escassa luminosidade, entre juncos alteados e papoilas desabrochadas, lagos silenciosos sem ondulação e cursos de água tranquilos, em cujas margens bancos de flores de infortúnios se suspendem, inclinando-se na turva luz, contendo nomes de reis e de rapazes de outrora: aqui estava Narciso a contemplar-se e também Jacinto, filho de Ébalo; Croco, de cabeleira dourada; Adónis matizado de púrpura e Eas de Salamina, inscrito com o trágico gemido. Todas as coisas que, carregadas de tristes choros e de sofrimentos de amor, prolongam dolorosas lembranças, mesmo quando a morte já passou, chamam de novo as heroínas às vidas que perderam. Aqui a grávida Sémele, defraudada das suas esperanças, lamenta as dores de parto entre os raios e, no vácuo, parte um berço queimado e agita o fogo inócuo de um raio imaginado. Lamentando a inútil dádiva com que outrora se havia alegrado, tendo o sexo masculino, Cénis sente pesar pelo regresso à sua anterior condição. Prócris ainda seca as suas feridas e estima a mão cruenta de Céfalo que a atacara. A rapariga Sestíaca transporta a sua lâmpada de barro fumegante e atira-se de cabeça a partir da sua torre. E a máscula Safo condenada a morrer pelas setas de amor pelo lésbio Fáon, ameaça saltar do nubloso Leucas. A triste Euripilo recusa o colar de Harmonia, infeliz pelo seu filho e desafortunada pelo seu marido. Também toda a história de Minos da elevada Creta resplandece como uma pintura esboçada. Pasífae segue as pegadas do seu níveo touro; a solitária Ariadne segura uma bola de cordel na sua mão; recorda as tabuinhas que atirou fora a desesperançada Fedra. Esta enverga um laço de forca; esta o simulacro vão de uma coroa, enquanto esta hesita por vergonha em entrar no seu esconderijo, na vitela forjada por Dédalo. 
Laodamia lamenta-se pelas duas noites passadas rapidamente em alegrias irreais, uma com o seu senhor vivo, a outra consigo morta. Noutro sítio, todas elas ferozes, pungidas por espadas pontiagudas, encontram-se Tisbe, Cânace e a Sidónia Elisa: esta traz o gládio do seu marido, a outra o do seu pai e a terceira, o do seu hóspede. Também vagueia aquela que, sobre as rochas de Latmo, se habituou a deplorar os repousos Endimion - a excitada Lua, com a sua tocha e o diadema brilhante. Outra centena mais, renovando as feridas das suas antigas paixões, revive as suas dores com prantos, simultaneamente doces e tristes.

No meio destas, irrompeu, sem mais, o Amor, dispersando a sombra dessa neblina obscura com as suas asas sibilantes. Todas reconhecem o mancebo e, como a sua memória retrocedesse, sentem-no como o responsável comum a todas, embora as nuvens negras tenham obscurecido o brilho do seu cinto dourado, a sua aljava e a chama da sua tocha resplandecente. Ainda assim, descobrem-no, tratam de colocar a sua força vã contra ele e, sobre o seu único inimigo, agora aceso num reino que não é o seu, onde poderia bater as suas asas, mas de modo fraco, sob o peso da densa noite, juntando-se num aglomerado, elas pressionam: quanto a ele, tremendo e procurando, em vão, escapar, arrastam-no para o meio da caterva. É escolhida uma árvore de mirtilo, bem conhecida nesse triste bosque e odiosa pelo castigo dos deuses. Aí Prosérpina, uma vez desprezada, havia crucificado Adónis, recordado da sua Vénus. Nesse tronco alto foi dependurado o Amor, as suas mãos atadas nas suas costas, os seus pés firmemente amarrados e, apesar dos seus choros, não lhe imputaram uma punição leve. Réu sem julgamento e sem juiz, o Amor é considerado culpado. Cada uma para se absolver de culpa, procura colocar as responsabilidades sobre a outra. Todas o censuram e preparam-se para lhe inculcarem as relíquias da morte que outrora haviam sofrido: estas são as suas armas escolhidas, esta é a doce vingança - cada qual desejosa de retaliar a dor com que havia sido morta. Uma segura um laço pronto, outra mostra o simulacro irreal de uma espada, outra mostra rios açambarcadores, outra rochedos pontiagudos, os horrores da fúria do mar, e uma profundidade sem ondas. Algumas oscilam tições e, tresloucadas, ameaçam-no com tochas que crepitam sem fogo. Mirra, com lágrimas cintilantes, abre o seu ventre maduro e atira sobre o rapaz trémulo as gotas de ambrósia cintilante que gotejam do seu tronco. Umas poucas fingem perdoar, mas apenas procuram gozá-lo e, com estiletes aguçados, derramam o seu sangue delicado, do qual brotam rosas, ou deixam a chama das suas lâmpadas vaguear a seu bel-prazer sobre a sua moldura frágil. A sua própria mãe também, a alma Vénus, culpada de uma 
vergonha similar, passa sem temor através da multidão tresloucada. E não se apressando a pedir pelo seu filho capturado, ela duplica o seu temor e incita a sua raiva enfraquecida com novo ódio. Faz recair sobre a acusação do seu filho a sua própria desgraça, pois ela suportou a rede escondida lançada pelo seu marido, quando encontrada no acto sexual com Marte; devido a que o helespôntico Príapo é objecto de riso, gozado pela sua deformidade; porque Érix é cruel e porque Hermafrodito não é de nenhum sexo. Mas as palavras não foram suficientes: com a sua grinalda de rosas, Vénus dourada bateu no jovem que chorou e temeu castigos ainda mais duros. Do seu corpo despedaçado, as rosas enroscadas extraíram líquido vermelho com muitas pancadas e, embora já matizado antes, ficou com um tom de vermelho ainda mais brilhante. Então as ameaças ferozes esmoreceram e o castigo pareceu demasiado grande para a ofensa, como se para deixar a culpa do lado de Vénus. As próprias heroínas intervêm, cada uma preferindo atribuir a culpa pela sua morte à crueldade do Fado. A seguir, a mãe carinhosa agradeceu-lhes por deporem as suas dores para desculpar o rapaz e perdoar as suas ofensas.

Tais visóes com os seus contornos nocturnos às vezes perturbam o seu descanso, desinquietando-o com temores sem sentido. Quando já tinha aguentado isso durante grande parte da noite, Cupido voa adiante. Finalmente erradicando as trevas do sono, esvoaça para os deuses acima e passa pelo portão de marfim."

\section{BiBLIOGRAFIA}

BONANNO, M. Patemi d'amore Apollonio, Teocrito e Saffo. In L'allusione necessaria. Ricerche intertestuali sulla poesia greca e latina. Roma: dell'Ateneo, 1990. p. 147-181.

CHARLES-MARIE, T. La sagesse grecque dans l'œuvre d'Ausone. Comptes-rendus des séances de l'Académie des Inscriptions et Belles-Lettres 130.1, p. 147-161, 1986.

CLARK, R. Catabasis: Vergil and the Wisdom Tradition. Amsterdam: B. R. Grüner, 1979.

COCKBURN, G. Aeneas and the Gates of Sleep: an etymological approach. Phoenix 46, p. 362-364, 1992.

DAVIS, N. Cupid at the Ivory Gates: Ausonius as a Reader of Vergil's Aeneid. CQ 30, p. 162-170, 1994. 
DOMINIK, W. Reading Virgil's Aeneid: the gates of sleep. Maia 48, p. 129-138, 1996.

DUFFIN, J. Lovers and livers: disease concepts in history. Toronto: University of Toronto Press, 2005.

EDWARDS, W. Ausonius, the Poet of the Transition. CJ 4.6, p. 250-259, 1909.

FAUTH, W. Cupido Cruciatur. GB 2, p. 39-60, 1974.

GARROD, H. The Oxford book of Latin verse, $p$. from the earliest fragments to the end of the Vth century A.D. Oxford: Clarendon Press, 1912.

GINDHART, M. Evolat ad superos Portaque evadit Eburna: Intertextuelle Strategien und Vergilparodie im Cupido cruciatus des Ausonius. RhM 149.2, p. 214-236, 2006.

HALDEMANN, P. Der "Cupido Cruciatus" des Ausonius und seine literarischen Vorgänger. Tutzing: Selbstverlag, 2000.

HARRIS, W. Dreams and experience in classical antiquity. Cambridge/London: Harvard University Press, 2009.

HOFMANN, H. Latin Fiction: The Latin novel in context. London/New York: Routledge, 1999.

KAUFMANN, H. Virgil's underworld in the mind of Roman late antiquity. Latomus 69, p. 150-160, 2010.

KILPATRICK, R. The stuff of doors and dreams. Vergilius 41, p. 63-70, 1995.

LAIRD, A. The Poetics and Afterlife of Virgil's Descent to the Underworld: Servius, Dante, Fulgentius and the Culex. PVS 24, p. 49-80, 2001.

LEBEK, W. Modestinus AL I 1,267 Shackleton Bailey, (= 273 Riese). ZPE 58, p. 37-45, 1985.

MILLER, P. The corporeal imagination: Signifying the holy in late ancient Christianity. Philadelphia: University of Pennsylvania Press, 2011.

MITCHELL, W. Picture Theory: Essays on Visual and Verbal Representation. Chicago/London: University of Chicago Press, 1994.

MONDIN, L. Genesi del Cupido Cruciatus. Lexis 23, p. 339-372, 2005. 
NAPIWOCKI, W. A critical text of the Gratiarum actio and the Cupido Cruciatur of D. Magnus Ausonius. Ann Arbor: University Microfilms International, 1985.

NILSSON, I. Plotting With Eros: Essays on the Poetics of Love and the Erotics of Reading. Copenhagen: Museum Tusculanum Press, 2009.

O'HARA, J. An Unconvincing Etymological Argument about Aeneas and the Gates of Sleep. Phoenix 50.3/4, p. 331-334, 1996.

PLAZA, J. Tradução Intersemiótica. São Paulo: Pioneira Thomson Learning, 2002.

PRAZ, M. Mnemosyne: The Parallel between Literature and the Visual Arts. London/Princeton: Princeton University Press/Oxford University Press, 1967.

REEVE, M. Some Manuscripts of Ausonius. Prometheus 3, p. 112-120, 1977.

ROSENMEYER, P. The Poetics of Imitation: Anacreon and the Anacreontic Tradition. Cambridge: Cambridge University Press, 2006.

SANTAELLA, L. Matrizes da linguagem e pensamento: sonora, visual, verbal. São Paulo: Iluminuras e FAPESP, 2001.

SANTINI, C. Ambiguità intertestuale nel 'Cupido cruciatus' di Ausonio. In ANTONINO, I. e MENESTÒ, E., Curiositas. Studi di cultura classica e medievale in onore di Ubaldo Pizzani. Napoli: Edizioni Scientifiche Italiane, 2002. p. 243-256.

TARRANT, R. Aeneas and the gates of sleep. CPh 77, p. 51-55, 1982.

VANNUCI L. Ausonio fra Virgilio e Stazio: a proposito dei modelli poetici del 'Cupido cruciatus'. A\& $\preccurlyeq$ 34, p. 39-54, 1989.

WARDEN, J. Patria praecepta: Lucretius and Virgil in the Underworld. Vergilius 46, p. 83-93, 2000. 